\title{
Variability in crop yields associated with climate anomalies in China over the past three decades
}

\author{
Fulu Tao ${ }^{1,3} \cdot$ Zhao Zhang $^{2} \cdot$ Shuai Zhang ${ }^{1} \cdot$ Reimund P. Rötter ${ }^{3}$
}

Received: 29 April 2015/Accepted: 20 December 2015/Published online: 7 January 2016

(C) Springer-Verlag Berlin Heidelberg 2016

\begin{abstract}
We used simple and explicit methods, as well as improved datasets for climate, crop phenology and yields, to address the association between variability in crop yields and climate anomalies in China from 1980 to 2008. We identified the most favourable and unfavourable climate conditions and the optimum temperatures for crop productivity in different regions of China. We found that the simultaneous occurrence of high temperatures, low precipitation and high solar radiation was unfavourable for wheat, maize and soybean productivity in large portions of northern, northwestern and northeastern China; this was because of droughts induced by warming or an increase in solar radiation. These climate anomalies could cause yield losses of up to $50 \%$ for wheat, maize and soybeans in the arid and semi-arid regions of China. High precipitation and low solar radiation were unfavourable for crop productivity throughout southeastern China and could cause yield losses of approximately $20 \%$ for rice and $50 \%$ for wheat and
\end{abstract}

Editor: Wolfgang Cramer.

Electronic supplementary material The online version of this article (doi:10.1007/s10113-015-0920-0) contains supplementary material, which is available to authorized users.

Fulu Tao

taofl@igsnrr.ac.cn

1 Key Laboratory of Land Surface Pattern and Simulation, Institute of Geographical Sciences and Natural Resources Research, Chinese Academy of Sciences, Beijing 100101, People's Republic of China

2 State Key Laboratory of Earth Surface Processes and Resource Ecology, Beijing Normal University, Beijing 100875, People's Republic of China

3 Natural Resources Institute Finland (Luke), 01301 Vantaa, Finland maize. High temperatures were unfavourable for rice productivity in southwestern China because they induced heat stress, which could cause rice yield losses of approximately $20 \%$. In contrast, high temperatures and low precipitation were favourable for rice productivity in northeastern and eastern China. We found that the optimum temperatures for high yields were crop specific and had an explicit spatial pattern. These findings improve our understanding of the impacts of extreme climate events on agricultural production in different regions of China.

Keywords Adaptation - Climate change Climate extremes $\cdot$ Drought $\cdot$ Impacts and vulnerability

\section{Introduction}

Climate variability and extreme climate events have been shown to increase in large regions of the world because of climate warming (Coumou and Rahmstorf 2012; Hartmann et al. 2013). An increased frequency of extreme weather events such as heat waves, prolonged droughts and flooding has been observed in recent decades (Zhai et al. 2005; Alexander et al. 2006; Coumou and Rahmstorf 2012). This has already had major negative impacts on agricultural production in much of the world (Battisti and Naylor 2009; Asseng et al. 2011; Lobell et al. 2012, 2013). Crop yields are quite sensitive to seasonal climate variability. Climate extremes can affect the survival of crops or plant organs (Sánchez et al. 2014) and have more serious consequences for food production and food insecurity than changes in the means of temperature and precipitation (Matsui et al. 2000; Lobell et al. 2013; Tao and Zhang 2013; Porter et al. 2014). Indeed, many of the deleterious impacts of global climate change have resulted from extreme weather events such as 
prolonged droughts, flooding and extreme temperatures, rather than from mean climate change (Salinger et al. 2000; Porter et al. 2014).

Nevertheless, many previous studies have focused on the impacts of mean climate change or climate trends on crop productivity (Tao et al. 2012; Zhang and Huang 2013; Ju et al. 2013; Xiong et al. 2014; Porter et al. 2014). Recent studies have focused on the response of crop production to climate variability and climate extremes (Battisti and Naylor 2009; Tao et al. 2013, 2015; Iizumi et al. 2013; Porter et al. 2014). An increasing number of studies have investigated the link between changes in the frequency and intensity of climate extremes and climate warming (Zhai et al. 2005; Alexander et al. 2006; Hartmann et al. 2013; Liu et al. 2011), as well as the impacts of climate variability and extremes on crop productivity. These studies have used various methods, including controlled environment experiments (Jagadish et al. 2007), field experiments (Lobell et al. 2013; Zhang et al. 2014; Tao et al. 2015), improved crop models (Challinor et al. 2005; Asseng et al. 2011, 2015; Tao and Zhang 2013), and statistical approaches (Lobell et al. 2012; Iizumi et al. 2013; Shuai et al. 2013a, b; Liu et al. 2014).

China has a high rate of climate variability on seasonal, interannual and decadal time scales due to its monsoon climate (Fu and Wen 1999). The high rate of variability in the monsoon climate strongly influences variability in both ecosystems and agricultural production (Fu and Wen 1999; Tao et al. 2004; Shuai et al. 2013a, b). Climate variability and extremes frequently cause meteorologically based agricultural disasters such as prolonged droughts, flooding, heat stress and cold damage (Wang et al. 2005; Tao et al. 2013). Every year, an average of $4.8 \times 10^{8}$ ha of croplands suffer from meteorological disasters, causing economic losses that amount to approximately $2 \times 10^{12}$ Chinese yuan over the entire country. Moreover, the frequency of meteorologically related agricultural disasters has increased along with climate warming over the past three decades (Tao et al. 2013; Zhang et al. 2014). Previous studies have investigated the impacts of droughts (e.g. Shi and Tao 2014) and extreme temperatures (e.g. Wang et al. 2014) on regional crop productivity, as well as the variability in crop yields associated with ENSO and the Asian monsoon (e.g. Tao et al. 2004; Shuai et al. 2013a, b; Liu et al. 2014).

To increase understanding of the impacts of climate variability and climate extremes on crop yields across China, in the present study, we use simple and explicit methods to address the following questions: (1) Which crops in which areas are most vulnerable to climate anomalies? (2) How much do crop yields vary in association with climate anomalies? Which climate conditions are favourable for crops (causing high yields), and which are unfavourable (causing low yields) in different regions of
China? (3) What are the optimum temperatures for crop productivity in various regions of China, beyond which crop productivity is negatively affected?

\section{Data and methods}

\section{Data}

In this study, we use the same climate, crop phenology and yield data as Tao et al. (2012), who investigated the impacts of climate trends on crop yields. Time series of yields for rice, wheat, maize and soybeans by county from 1980 to 2008 were obtained from the Agricultural yearbook for each province (autonomous region or municipality), which is published annually by the China Agriculture Press in Beijing. We also used some unpublished data from county-level census bureaus. A preliminary quality check was conducted and observations were flagged as outliers when they fell outside the range of biophysically attainable yields. In total, we used yield time series from 1670 counties for rice, 2021 counties for wheat, 2111 counties for maize and 1943 counties for soybeans. These data spanned the period from 1980 to 2008 and covered the major crop production regions.

Phenological records (observed in research plots) for rice, wheat, maize and soybeans from approximately 300 experimental agro-meteorological stations across the major production regions were obtained from the China meteorological administration (2009). We used data from 321, 288, 258 and 80 experimental agro-meteorological stations, respectively, for rice, wheat, maize and soybeans. These records included the dates of major crop phenological events since 1980, such as sowing, transplanting, flowering and maturity. For each phenological event, the mean date from 1980 to 2008 was first computed at each station. Next, the mean date of the event for each county was computed from the nearest station. These detailed phenological records provide a unique opportunity to determine exact crop growing periods and consequently the seasonal climate during the growing period of each crop by county.

Daily weather data including maximum $\left(T_{\max }\right)$ and mean temperatures $\left(T_{\text {mean }}\right)$, precipitation and hours of sunshine were obtained from 756 national standard stations (NSSs) of the CMA. Inhomogeneity in daily temperature series is almost unavoidable due to various non-natural changes such as changes in the observing location, environment and other factors (Manton et al. 2001; Li and Yan 2009). In the present study, we determined the daily $T_{\max }$ and $T_{\text {mean }}$ using the China homogenized historical temperature dataset (Li and Dong 2009), in which inhomogeneities in the daily $T_{\text {max }}$ and $T_{\text {mean }}$ series from 1960 to 2008 at 549 NSSs were analysed and corrected using the multiple analysis of 
series for homogenization software package ( $\mathrm{Li}$ and Yan 2009). Daily sunshine hours was observed at the 756 NSSs of CMA, although daily solar radiation (SRD) was only observed at 122 NSSs. The SRD at the 756 NSSs was computed from hours of sunshine using the AngströmPrescott (A-P) equation (Prescott 1940). Across the 122 NSSs, the root-mean-square error (RMSE) between the estimated and observed SRD was $3.2\left(\mathrm{MJm}^{-2} \mathrm{day}^{-1}\right)$ and the coefficient of determination $\left(r^{2}\right)$ was 0.8 . At the county level, daily $T_{\max }, T_{\text {mean }}$ and SRD for each county were computed from the nearest three NSSs using triangular irregular network interpolation. Because spatial interpolation of daily precipitation can cause greater uncertainties than for daily $T_{\max }, T_{\text {mean }}$ and SRD, daily precipitation in each county was determined using the observations from the nearest NSS. The methods are robust because the meteorological and experimental agro-meteorological stations are densely spaced enough to be representative of climate and crop phenology for each county; this is particularly true in the major production regions (see Fig. S1 in Tao et al. 2012).

\section{Methods}

First, the time series of yields for rice, wheat, maize and soybeans by county from 1980 to 2008 were linearly detrended; this resulted in detrended yield series that reflect the effects of interannual climate variability. The detrended yield, or yield anomaly $\left(\mathrm{Yd} \__{-} a\right)$, in county $i$ and year $t$ $\left(\mathrm{Yd} \_a_{i, t}\right)$ was expressed as a percentage using the following equation:

$\mathrm{Yd} \_a_{i, t}=\left(\mathrm{Yd} \_o_{i, t}-\mathrm{Yd} \_t_{i, t}\right) / \mathrm{Yd} \_t_{i, t} \times 100 \%$,

where Yd_o $o_{i, t}$ and $Y \mathrm{Yd}_{-} t_{i, t}$ represent the observed yield and trend yield estimated by a linear regression model in county $i$ and year $t$, respectively. The standard deviation (SD) of Yd_ $a_{i, t}$ during 1980-2008 was also computed to determine the variability in crop yields associated with climate anomalies.

Next, the Yd $\_a_{i, t}$ series from 1980 to 2008 were sorted, and for each county, the climate anomalies were determined for the five highest yielding years and the five lowest yielding years; these were compared with the normal years (i.e. all of the remaining years other than the five highest and lowest yielding years). For each county, the spatial patterns of the climate conditions favourable for higher yields were identified for rice, wheat, maize and soybeans; the same was done for the unfavourable climate conditions associated with lower yields.

Finally, the spatial patterns of the optimum $T_{\max }$ and $T_{\text {mean }}$ for crop productivity were identified for rice, wheat, maize and soybeans for each county.

\section{Results}

\section{Variability in crop yields associated with climate anomalies}

With climate variability from 1980-2008, Rice Yd_a was relatively variable in northern, northeastern and northwestern China, but was relatively stable in southern China (Fig. 1). Wheat $\mathrm{Yd} \_a$ was relatively variable in northern and northeastern China (Fig. 1). The variability in maize Y $\mathrm{Yd} \_a$ was quite large, with a SD above $20 \%$ occurring in large areas across the major maize production regions of China (Fig. 1). Soybean Yd_a was also highly variable, particularly in northern and northeastern China (Fig. 1).

\section{Yield and climate anomalies in the lowest and the highest yielding years}

For rice, in the five lowest yielding years, Yd_a had a value of approximately $-50 \%$ in parts of northeastern China and $-20 \%$ in southern China (Fig. 2a). In comparison with the normal years, the climate in the lowest yielding years was generally characterized by lower temperatures (Fig. 2b), higher precipitation (Fig. 2c) and lower SRD (Fig. 2d) in northeastern China; however, higher temperatures (Fig. 2b), lower precipitation (Fig. 2c) and higher SRD (Fig. 2d) occurred in southwestern China. In the five highest yielding years, rice Yd_ $a$ had a value of approximately $50 \%$ in parts of northeastern China and $20 \%$ in southern China (Fig. 2e). Compared to the normal years, the climate in the highest yielding years was generally characterized by higher temperatures (Fig. 2f) and lower precipitation (Fig. 2g) in northeastern China; and by higher temperatures (Fig. 2f), lower precipitation (Fig. 2g) and higher SRD (Fig. 2h) in eastern China.

For wheat, in the five lowest yielding years, $\mathrm{Yd} \_a$ was approximately $-50 \%$ in northern and northeastern China, and $-40 \%$ in other regions (Fig. 3a). In comparison with normal years, the climate in the lowest yielding years was generally characterized by higher temperatures (Fig. S1B), lower precipitation (Fig. S1C) and higher SRD (Fig. S1D) in northern, northeastern, northwestern and southwestern China; and by higher temperatures (Fig. S1B), higher precipitation (Fig. S1C) and lower SRD (Fig. S1D) in southeastern China. In the five highest yielding years, Yd_ $a$ was approximately $50 \%$ in northern and northeastern China, and $30 \%$ in other regions (Fig. S1E). In comparison with normal years, the climate in the highest yielding years was generally characterized by higher temperatures (Fig. S1F), higher precipitation (Fig. S1G) and lower SRD (Fig. S1H) in northern and northeastern China; 


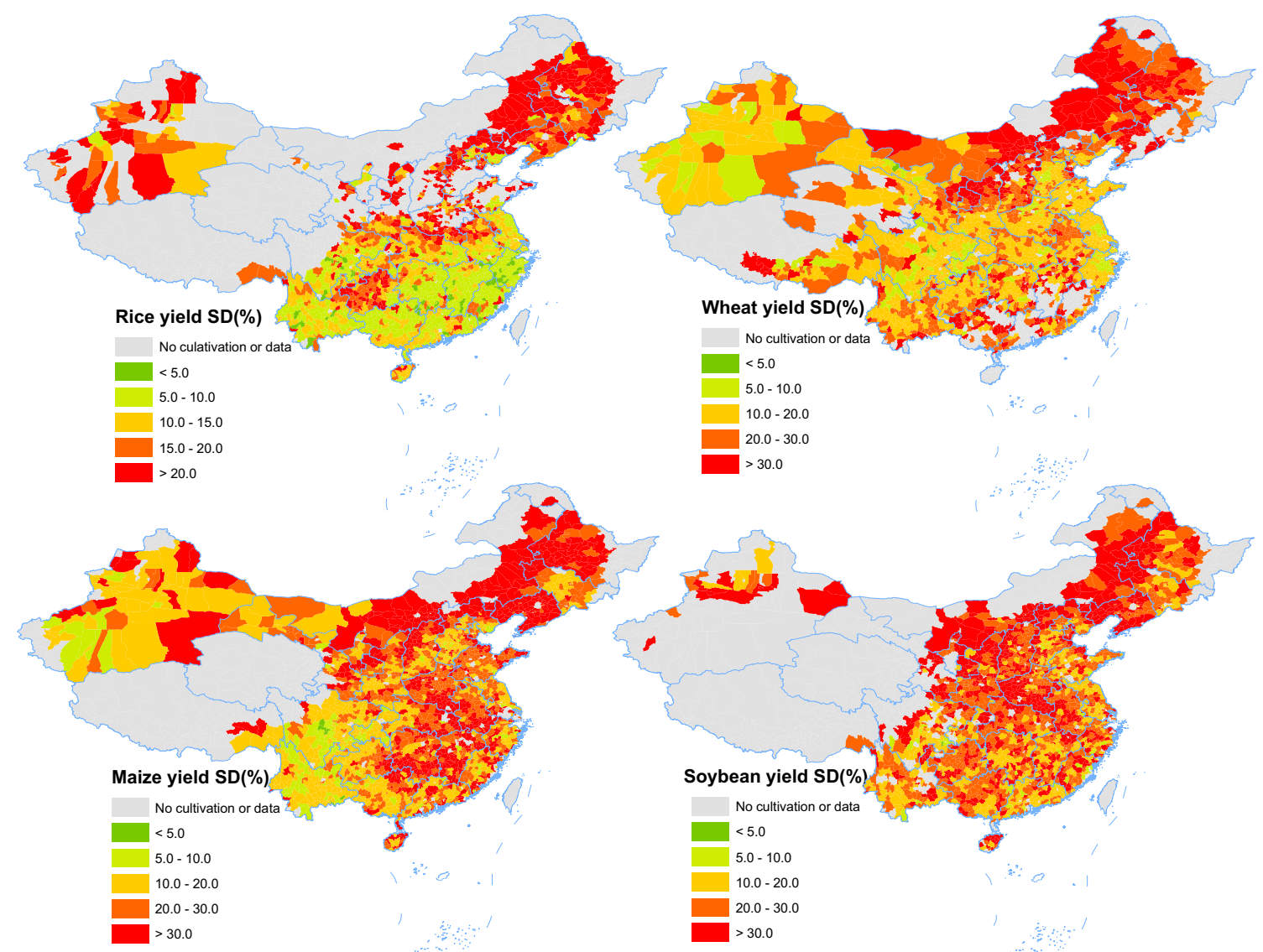

Fig. 1 Standard deviations (SD) of crop yield anomaly during 1980-2008 for rice, wheat, maize and soybean

however, lower temperatures (Fig. S1F), lower precipitation (Fig. S1G) and higher SRD (Fig. S1H) occurred in southeastern China.

For maize, in the five lowest yielding years, Yd_ $a$ was approximately $-50 \%$, particularly in northern and northeastern China (Fig. S2A). In comparison with normal years, the climate in the lowest yielding years was generally characterized by higher temperatures (Fig. S2B), lower precipitation (Fig. S2C) and higher SRD (Fig. S2D) in northern, northeastern and northwestern China; and by lower temperatures (Fig. S2B), higher precipitation (Fig. S2C) and lower SRD (Fig. S2D) in southeastern China. In the five highest yielding years, Yd_ $a$ was approximately $50 \%$ in northern, northeastern China and southeastern China (Fig. S2E). In comparison with normal years, the climate in the highest yielding years was generally characterized by lower temperatures (Fig. S2F), higher precipitation (Fig. S2G) and lower SRD (Fig. S2H) in northern and northeastern China; however, lower temperatures (Fig. S2F), lower precipitation (Fig. S2G) and higher SRD (Fig. S2H) occurred in southeastern China.
Fig. 2 Anomalies of rice yield (a, e), mean temperature $(\mathbf{b}, \mathbf{f})$, precipitation $(\mathbf{c}, \mathbf{g})$ and solar radiation $(\mathbf{d}, \mathbf{h})$ in the five lowest yielding years $(\mathbf{a}, \mathbf{b}, \mathbf{c}, \mathbf{d})$ and the five highest yielding years $(\mathbf{e}, \mathbf{f}, \mathbf{g}, \mathbf{h})$ during 1980-2008

For soybeans, in the five lowest yielding years, Yd_ $a$ was approximately $-50 \%$, particularly in northern and northeastern China (Fig. S3A). In comparison with normal years, the climate in the lowest yielding years was characterized by higher temperatures (Fig. S3B), lower precipitation (Fig. S3C) and higher SRD (Fig. S3D) in northern and northeastern China; and by higher precipitation (Fig. S3C) and lower SRD (Fig. S3D) in eastern China. In the five highest yielding years, $\mathrm{Yd} \_a$ was approximately $50 \%$, particularly in northern and northeastern China (Fig. S3E). In comparison with normal years, the climate in the highest yielding years was generally characterized by higher precipitation (Fig. S3G) in northern and northeastern China; and by lower precipitation (Fig. S3G) and higher SRD (Fig. S3H) in eastern China. 

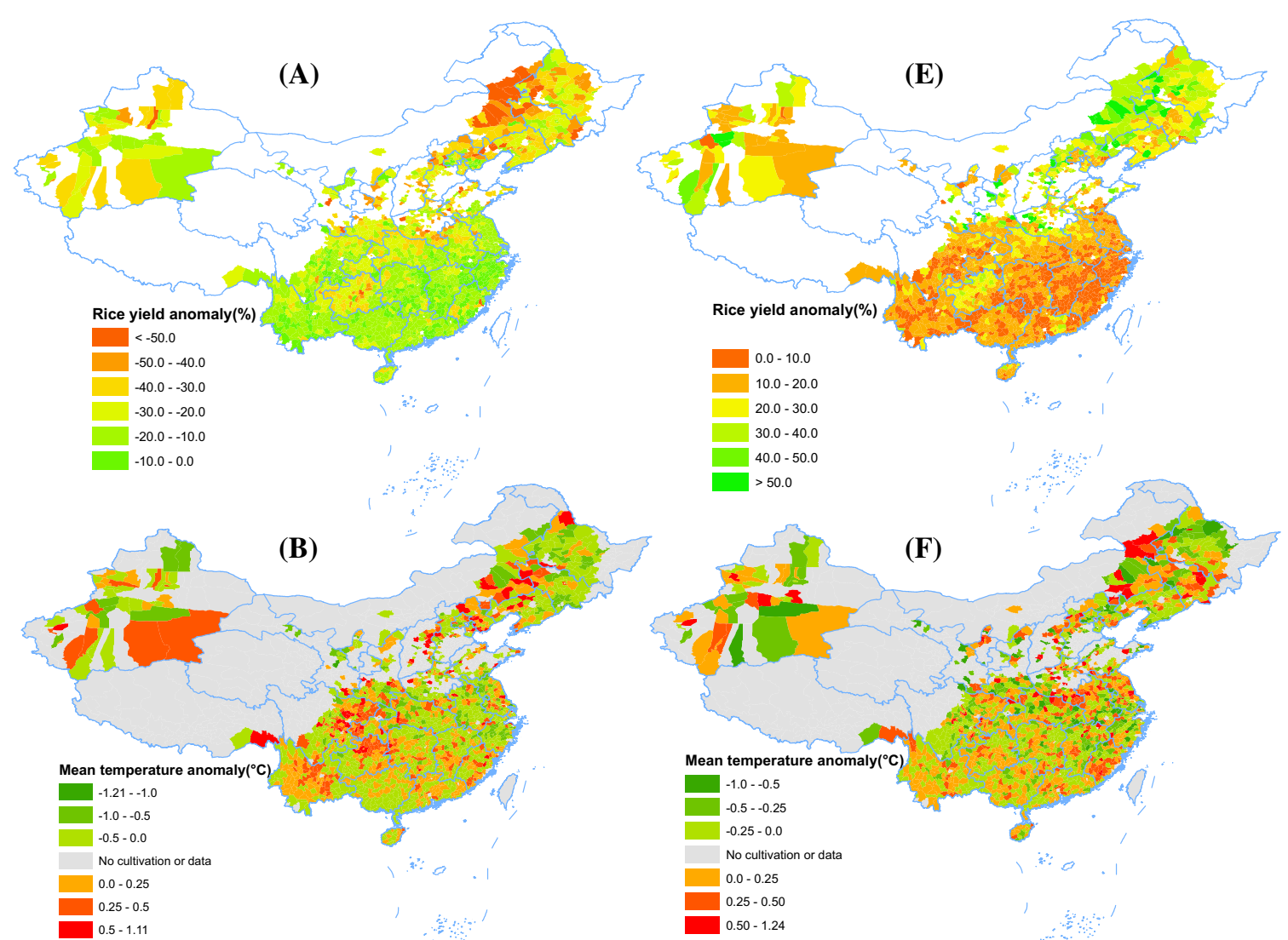

(B)
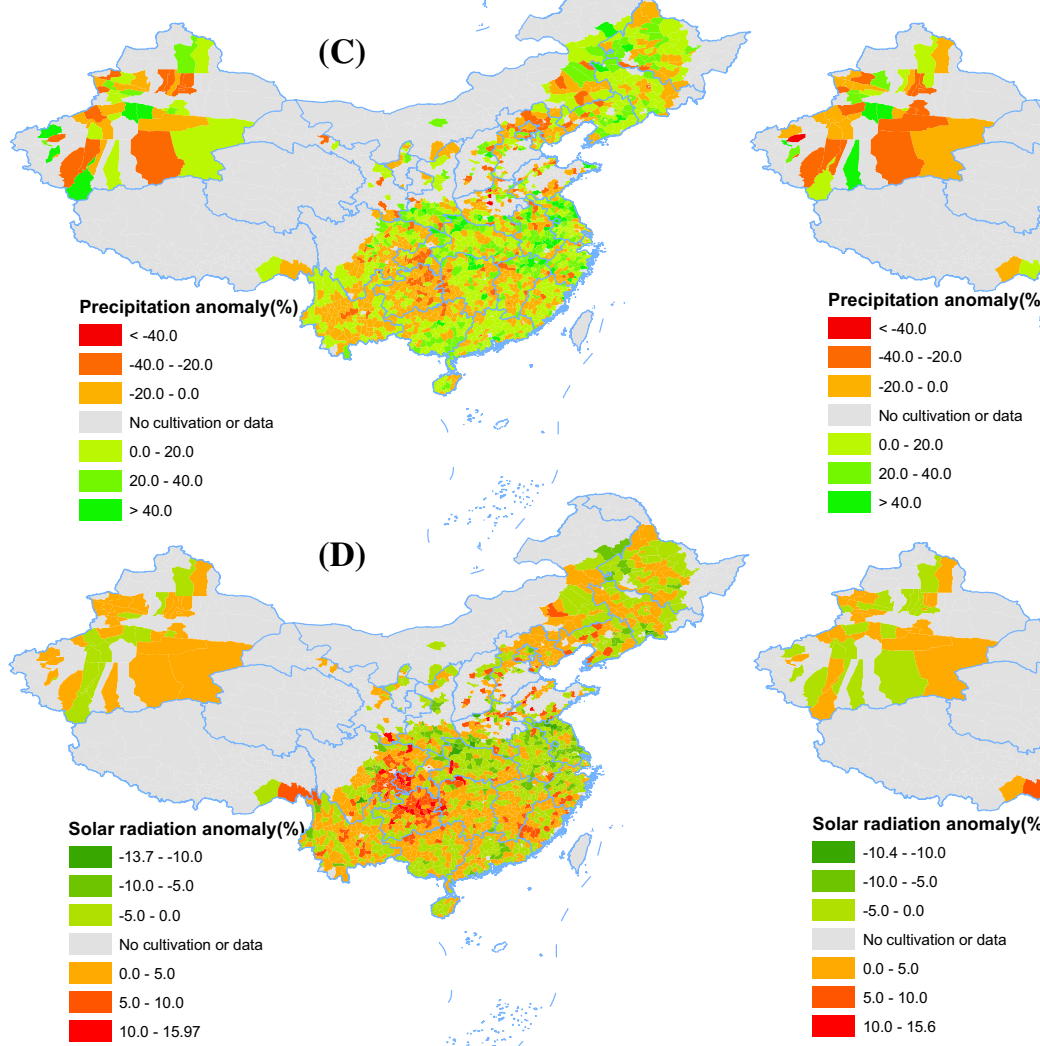

(D)

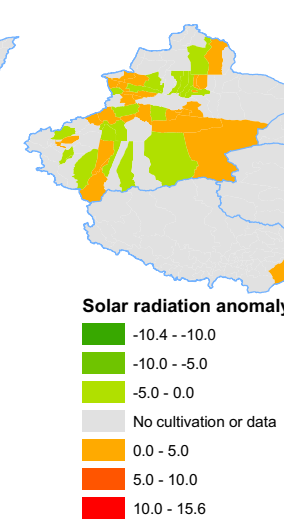

(F)

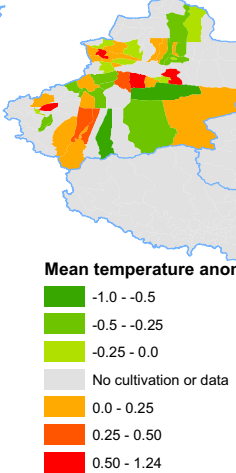

(G)

(H) 
Maximum and mean temperatures associated with the highest yields

For rice, in northern and northeastern China, the mean $T_{\max }$ ( $\left.T_{\text {mean }}\right)$ during the growing period in the five highest yielding years ranged from $25\left(20{ }^{\circ} \mathrm{C}\right)$ to $29{ }^{\circ} \mathrm{C}\left(24{ }^{\circ} \mathrm{C}\right)$ (Fig. 3a, b). In southern China, these values ranged from 29 $\left(24{ }^{\circ} \mathrm{C}\right)$ to $34{ }^{\circ} \mathrm{C}\left(28{ }^{\circ} \mathrm{C}\right)$ (Fig. 3a, b).

For wheat, in northern, northeastern and northwestern China, the mean $T_{\max }\left(T_{\text {mean }}\right.$ ) during the growing period in the five highest yielding years ranged from $20\left(14^{\circ} \mathrm{C}\right)$ to $33.8^{\circ} \mathrm{C}\left(26^{\circ} \mathrm{C}\right)$ (Fig. 3c, d). In central China, these values ranged from $5\left(<5^{\circ} \mathrm{C}\right)$ to $15.0^{\circ} \mathrm{C}\left(11.0^{\circ} \mathrm{C}\right)$, and in southern China they ranged from $15\left(11^{\circ} \mathrm{C}\right)$ to $33.8^{\circ} \mathrm{C}$ $\left(26^{\circ} \mathrm{C}\right)$ (Fig. 3c, d).

For maize, in northern and northeastern China, the mean $T_{\text {max }}\left(T_{\text {mean }}\right)$ during the growing period in the five highest yielding years ranged from $23\left(15^{\circ} \mathrm{C}\right)$ to $29.0^{\circ} \mathrm{C}\left(21{ }^{\circ} \mathrm{C}\right)$ in northern and northeastern China (Fig. 3e, f). In central, northwestern and southern China, the corresponding values ranged from $26\left(21{ }^{\circ} \mathrm{C}\right)$ to $32.0^{\circ} \mathrm{C}\left(27^{\circ} \mathrm{C}\right)$ (Fig. 3e, f).

For soybeans, in northern, northeastern and northwestern China, the mean $T_{\text {max }}\left(T_{\text {mean }}\right)$ during the growing period in the five highest yielding years ranged from 23 $\left(18^{\circ} \mathrm{C}\right)$ to $29.0^{\circ} \mathrm{C}\left(21^{\circ} \mathrm{C}\right)$ (Fig. $\left.3 \mathrm{~g}, \mathrm{~h}\right)$. In central and southern China, the corresponding values ranged from 26 $\left(21{ }^{\circ} \mathrm{C}\right)$ to $32.0{ }^{\circ} \mathrm{C}\left(27.0^{\circ} \mathrm{C}\right)$ (Fig. $\left.3 \mathrm{~g}, \mathrm{~h}\right)$.

\section{Discussion}

\section{Variability in crop yields was larger in northern and northeastern China}

The detrended crop yields (i.e. Yd_a) mainly reflect interannual climate variability; therefore, changes in $\mathrm{Yd} \_a$ indicate the integrated impacts of climate variability on crop yields. The simple and explicit methods used in this study to investigate climate variability and crop productivity have the advantage over complex methods such as process-based crop models and statistical approaches that their results are less affected by uncertainties from input data, biophysical parameters and the processes in crop models. Yd_a showed high climate variability in northern and northeastern China, with an SD above $20 \%$ for rice and above $30 \%$ for other crops, mainly due to the monsoon climate in the regions, which induced large interannual variability in precipitation and temperature. These results are consistent with several previous studies (Shuai et al. 2013a, b; Shi and Tao 2014; Zhang et al. 2014). The association between crop yield variability and increasing climate variability and climate extremes is large enough to warrant further study.
Fig. 3 Maximum (a, c, e, g) and mean temperature $(\mathbf{b}, \mathbf{d}, \mathbf{f}, \mathbf{h})$ during crop growing period in the five highest yielding years during 1980-2008 for rice (a, b), wheat (c, d), maize (e, f) and soybean $(\mathrm{g}, \mathbf{h})$

\section{Favourable and unfavourable climate conditions for regional crop production}

Comparisons between the climate conditions in the highest and lowest yielding years are useful for identifying favourable versus unfavourable climate conditions for regional crop production. For example, when higher temperatures, lower precipitation and higher SRD occurred simultaneously, the resulting conditions were unfavourable for wheat, maize and soybeans in large areas of northern, northwestern and northeastern China because of droughts induced by warming or increased solar radiation. Higher precipitation and lower SRD were unfavourable for all crops because continuous rainy days and low solar radiation are critical limiting factors for crop productivity in southeastern China (Tao et al. 2012, 2013; Shuai et al. 2013a, b; Zhang and Huang 2013; Xiong et al. 2014; Li et al. 2015). Higher temperatures were unfavourable for rice productivity in southwestern China because of heat stress (Tao et al. 2013; Wang et al. 2014). These findings are supported by the results of previous studies (e.g. Tao et al. 2012; Lobell et al. 2013; Liu et al. 2014; Xiong et al. 2014; Li et al. 2015). For example, several previous studies that examined census yield data for mixed irrigation and rain-fed crops at the county and provincial scale showed that precipitation was a key factor affecting crop yield variability in arid and semi-arid regions of China (Tao et al. 2012; Zhang and Huang 2013; Liu et al. 2014; Xiong et al. 2014; Li et al. 2015; Zhang et al. 2015). The results are also supported by several recent artificial field warming experiments. For example, an infrared warming field experiment showed that wheat growth and yields on the North China Plain were significantly increased by an artificial warming of $2.5^{\circ} \mathrm{C}$ (Fang et al. 2015). Rice growth and yields were also enhanced by a field infrared warming of $2.32{ }^{\circ} \mathrm{C}$ in northeast China (Zhang et al. 2013).

\section{Optimum temperatures for crop productivity in different regions}

We estimated the optimum $T_{\max }$ and $T_{\text {mean }}$ using an empirical approach. The results showed that the optimum $T_{\text {max }}$ and $T_{\text {mean }}$ were crop specific and had explicit spatial patterns, which were closely related to latitude and altitude. The optimum $T_{\max }$ and $T_{\text {mean }}$ derived in this study are well within the ranges reported in previous studies (Sánchez et al. 2014). It is difficult to identify the 

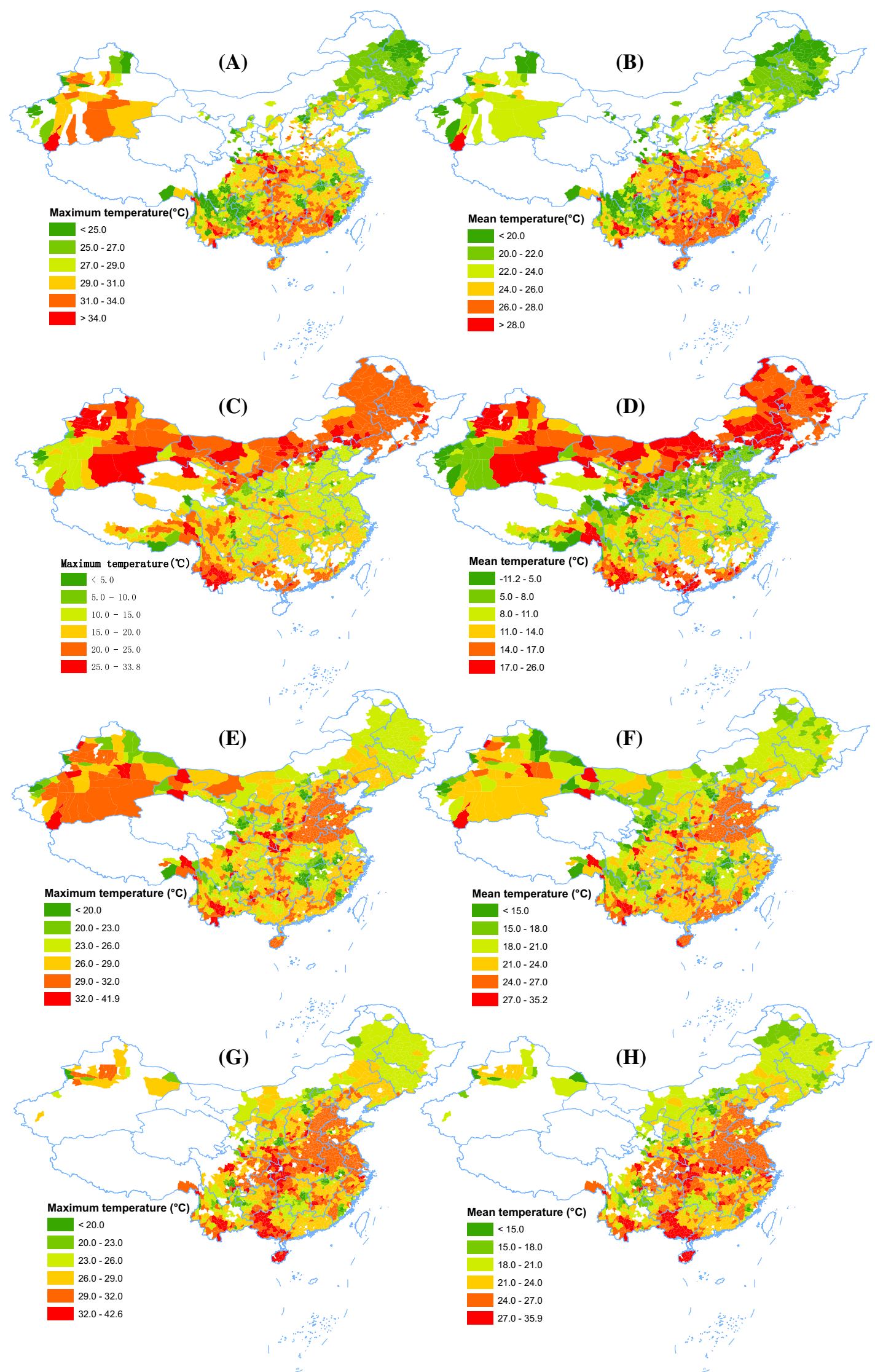
optimum $T_{\max }$ and $T_{\text {mean }}$ for crop growth and yields because these values differ depending on the crop growth stages (Sánchez et al. 2014) and theoretically should be determined in controlled-environmental experiments. Nevertheless, estimates using empirical approaches are useful because spatial information for the two parameters is currently scarce; however, this information is crucial for spatially explicit parameterization of crop models and consequently for improving climate impact modelling studies at both regional and national scales. Furthermore, impact assessments of the optimum temperatures for crop growth and productivity, which are increasingly important, have large uncertainties (Craufurd and Wheeler 2009; Zhang and Tao 2013; Asseng et al. 2015). Thus, determining the optimum $T_{\max }$ and $T_{\text {mean }}$ for different crops in various climate zones is important for understanding the impacts of climate extremes and improving modelling studies of these impacts.

\section{Uncertainties and shortcomings}

There are several potential uncertainties in this study. Although the meteorological and experimental agro-meteorological stations that provided the data for this study are relatively dense, and as such are likely representative of climate and crop phenology for each county in the major production regions, the different spatial interpolation methods used at each station could affect the results to some extent. In addition, different detrending methods can affect the magnitude of the estimates, although they would not affect the sign of the estimates or the general conclusions (Lobell et al. 2011). In this study, a linear detrending method was applied to the yield series because it was generally suitable for all of the counties. We note that while it might not be the best method for some counties, using a consistent method produced less error over all of the counties. Finally, the complex characteristics of this study, such as the patchy patterns of yield and climate anomalies, as well as the simultaneous effects of multiple climate variables, complicate the statistical analyses.

\section{Conclusions}

We used simple and explicit methods, and improved datasets for climate, crop phenology and yields to address the variability in crop yields associated with climate anomalies in China over the past three decades. We found that there was high variability in the yields of major crops, particularly in northern and northeastern China. We also identified the most favourable and unfavourable climate conditions for yields of various crops, as well as the optimum $T_{\max }$ and $T_{\text {mean }}$, over different regions of China. Our results highlight the importance of accounting for the roles of climate variability and climate extremes in studies of climate change impacts and adaptation. The findings improve our understanding of the impacts of climate extremes on crop productivity in different regions and are relevant to climate impact modelling on a large scale. Moreover, our results, together with seasonal weather forecasting information, could also be applied to develop a regional food security warming system.

Acknowledgments This study is supported by the National Science Foundation of China (Project Nos. 41571088, 31561143003 and 41571493), partly supported by the Finnish Ministry of Agriculture and Forestry via FACCE-MACSUR and by Luke via the strategic MODAGS project. We are grateful to two anonymous reviewers for providing highly valuable comments on earlier drafts of this manuscript.

\section{References}

Alexander LV, Zhang X, Peterson TC, Caesar J, Gleason B, Klein Tank AMG et al (2006) Global observed changes in daily climate extremes of temperature and precipitation. J Geophys Res Atmos 111:D05109. doi:10.1029/2005JD006290

Asseng S, Foster IAN, Turner NC (2011) The impact of temperature variability on wheat yields. Glob Change Biol 17:997-1012. doi:10.1111/j.1365-2486.2010.02262.x

Asseng S, Ewert F, Martre P, Rotter RP et al (2015) Rising temperatures reduce global wheat production. Nat Clim Change 5:143-147. doi:10.1038/nclimate2470

Battisti DS, Naylor RL (2009) Historical warnings of future food insecurity with unprecedented seasonal heat. Science 323:240-244. doi:10.1126/science. 1164363

Challinor AJ, Wheeler TR, Craufurd PQ, Slingo JM (2005) Simulation of the impact of high temperature stress on annual crop yields. Agric For Meteorol 135:180-189. doi:10.1016/j.agrfor met.2005.11.015

China Meteorological Administration (2009) Grade of chilling damage for rice and maize. Meteorological industry standard of People's Republic of China (QX/T 101-2009). Beijing: China Meteorological Press. Delivered June 7, 2009, Implemented November 1, 2009

Coumou D, Rahmstorf S (2012) A decade of weather extremes. Nat Clim Change 2:491-496. doi:10.1038/nclimate1452

Craufurd PQ, Wheeler TR (2009) Climate change and the flowering time of annual crops. J Exp Bot 60:2529-2539. doi:10.1093/jxb/ erp196

Fang S, Cammarano D, Zhou G, Tan K, Ren S (2015) Effects of increased day and night temperature with supplemental infrared heating on winter wheat growth in North China. Eur J Agron 64:67-77. doi:10.1016/j.eja.2014.12.012

Fu C, Wen G (1999) Variation of ecosystems over East Asia in association with seasonal, interannual and decadal monsoon climate variability. Clim Change 43:477-494. doi:10.1023/A: 1005471600483

Hartmann DL, Klein Tank AMG, Rusticucci M, Alexander LV, Brönnimann S, Charabi Y, Dentener FJ, Dlugokencky EJ, Easterling DR, Kaplan A, Soden BJ, Thorne PW, Wild M, Zhai PM (2013) Observations: atmosphere and surface. In: Climate 
change 2013: the physical science basis. Contribution of working group I to the fifth assessment report of the intergovernmental panel on climate change. Cambridge University Press, Cambridge, United Kingdom and New York, NY

Iizumi T, Sakuma H, Yokozawa M, Luo J, Challinor AJ, Brown ME, Sakurai G, Yamagata T (2013) Prediction of seasonal climateinduced variations in global food production. Nat Clim Change 3:904-908. doi:10.1038/nclimate1945

Jagadish SVK, Craufurd PQ, Wheeler TR (2007) High temperature stress and spikelet fertility in rice (Oryza sativa L.). J Exp Bot 58:1627-1635. doi:10.1093/jxb/erm003

Ju H, van der Velde M, Lin E, Xiong W, Li Y (2013) The impacts of climate change on agricultural production systems in China. Clim Change 1-2:313-324. doi:10.1007/s10584-013-0803-7

Li QX, Dong WJ (2009) Detection and adjustment of undocumented discontinuities in Chinese temperature series using a composite approach. Adv Atmos Sci 26:143-153. doi:10.1007/s00376-0090143-8

Li Z, Yan ZW (2009) Homogenized daily mean/maximum/minimum temperature series for China from 1960-2008. Atmos Ocean Sci Lett 2:237-243

Li Y, Xiong W, Hu W, Berry P, Ju H, Lin E, Wang W, Li K, Pan J (2015) Integrated assessment of China's agricultural vulnerability to climate change: a multi-indicator approach. Clim Change 128:355-366. doi:10.1007/s10584-014-1165-5

Liu B, Henderson M, Xu M, Zhang Y (2011) Observed changes in precipitation on the wettest days of the year in China, 1960-2000. Int J Clim 31:487-503. doi:10.1002/joc.2089

Liu Y, Yang X, Wang E, Xue C (2014) Climate and crop yields impacted by ENSO episodes on the North China Plain: 1956-2006. Reg Environ Change 14:49-59. doi:10.1007/ s10113-013-0455-1

Lobell DB, Schlenker W, Costa-Roberts J (2011) Climate trends and global crop production since 1980. Science 333:616-620. doi:10. 1126/science. 1204531

Lobell DB, Sibley A, Ortiz-Monasterio JI (2012) Extreme heat effects on wheat senescence in India. Nat Clim Change 2:186-189. doi:10.1038/nclimate1356

Lobell DB, Hammer GL, McLean G, Messina C, Roberts MJ, Schlenker W (2013) The critical role of extreme heat for maize production in the United States. Nat Clim Change 3:497-501. doi:10.1038/nclimate 1832

Manton MJ, Della-Marta PM, Haylock MR, Hennessy KJ et al (2001) Trends in extreme daily rainfall and temperature in Southeast Asia and the South Pacific: 1961-1998. Int J Climatol 21:269-284. doi:10.1002/joc.610

Matsui T, Omasa K, Horie T (2000) High temperature at flowering inhibits swelling of pollen grains, a driving force for thecae dehiscence in rice (Oryza sativa L.). Plant Prod Sci 3:430-434

Porter JR, Xie L, Challinor AJ, Cochrane K, Howden SM, Iqbal MM, Lobell DB, Travasso MI (2014) Food security and food production systems. In: Climate change 2014: impacts, adaptation, and vulnerability. Part A: global and sectoral aspects. Contribution of working group II to the fifth assessment report of the intergovernmental panel on climate change, Cambridge University Press, Cambridge, United Kingdom and New York, NY, pp 485-533

Salinger MJ, Stigter CJ, Das HP (2000) Agrometeorological adaptation strategies to increasing climate variability and climate change. In: Sivakumar MVK, Stigter CJ, Rijks DA (eds) Agrometeorology in the twenty-first century needs and perspectives, vol 103, pp 167-184

Sánchez B, Rasmussen A, Porter JR (2014) Temperatures and the growth and development of maize and rice: a review. Glob Change Biol 20:408-417. doi:10.1111/gcb.12389
Shi W, Tao F (2014) Spatio-temporal distributions of climate disasters and the response of wheat yields in China from 1983 to 2008. Nat Hazards 74:569-583. doi:10.1007/s11069-014$1197-1$

Shuai J, Zhang Z, Liu X, Chen Y, Wang P, Shi P (2013a) Increasing concentrations of aerosols offset the benefits of climate warming on rice yields during 1980-2008 in Jiangsu province, China. Reg Environ Change 13:287-297. doi:10.1007/s10113-012-0332-3

Shuai J, Zhang Z, Sun DZ, Tao F, Shi P (2013b) ENSO, climate variability and crop yields in China. Clim Res 58:133-148. doi: $10.3354 / \mathrm{cr} 01194$

Tao F, Zhang Z (2013) Climate change, high temperature stress, rice productivity and water use in Eastern China: a new superensemble-based probabilistic projection. J Appl Meteorol Climatol 52:531-551. doi:10.1175/JAMC-D-12-0100.1

Tao F, Yokozawa M, Zhang Z, Hayashi Y, Grassl H, Fu C (2004) Variability in climatology and agricultural production variability in China in association with East Asian monsoon and El Niño Southern Oscillation. Clim Res 28:23-30. doi:10.3354/cr028023

Tao F, Zhang Z, Zhang S, Zhu Z, Shi W (2012) Response of crop yields to climate trends since 1980 in China. Clim Res 54:233-247. doi:10.3354/cr01131

Tao F, Zhang S, Zhang Z (2013) Changes in rice disasters across China in recent decades and the meteorological and agronomic causes. Reg Environ Change 13:743-759. doi:10.1007/s10113012-0357-7

Tao F, Zhang Z, Zhang S, Rötter RP (2015) Heat stress impacts on wheat growth and yield were reduced in the Huang-Huai-Hai plain of China in the past three decades. Eur J Agron 71:44-52. doi:10.1016/j.eja.2015.08.003

Wang S, Huo Z, Guo J, Wang C (2005) Agrometeorological disaster risk management in China. In: Das HP, Sivakumar MVK, Motha RP (eds) Natural disasters and extreme events in agriculture. Springer, Heidelberg, pp 241-258

Wang P, Zhang Z, Song X, Chen Y, Wei X, Shi P, Tao F (2014) Temperature variations and rice yields in China: historical contributions and future trends. Clim Change 124:777-789. doi:10.1007/s10584-014-1136-x

Xiong W, Holman I, You L, Yang J, Wu W (2014) Impacts of observed growing-season warming trends since 1980 on crop yields in China. Reg Environ Change 14:7-16. doi:10.1007/ s10113-013-0418-6

Zhai PM, Zhang XB, Pan XH (2005) Trends in total precipitation and frequency of daily precipitation extremes over China. J Clim 18:1096-1108. doi:10.1175/JCLI-3318.1

Zhang T, Huang Y (2013) Estimating the impacts of warming trends on wheat and maize in China from 1980 to 2008 based on county level data. Int J Climatol 33:699-708. doi:10.1002/joc.3463

Zhang S, Tao F (2013) Modeling the response of rice phenology to climate change and variability in different climatic zones: comparisons of five models. Eur J Agron 45:165-176. doi:10. 1016/j.eja.2012.10.005

Zhang J, Zhang J, Yao F, Men Y, Gao X (2013) Effects of free air temperature increasing on the rice growth and grain yield in Northeast China. Chin J Ecol 32:15-21

Zhang Z, Wang P, Chen Y, Zhang S, Tao F, Liu X (2014) Spatial pattern and decadal change of agro-meteorological disasters in the main wheat production area of China during 1991-2009. J Geogr Sci 24:387-396. doi:10.1007/s11442-014-1095-1

Zhang Z, Song X, Tao F, Zhang S, Shi W (2015) Climate trends and crop production in China at county scale, 1980-2008. Theory Appl Climatol. doi:10.1007/s00704-014-1343-4 